\title{
Immunological outcomes of Tenofovir versus Zidovudine-based regimens among people living with HIV/AIDS: a two years retrospective cohort study
}

Teshale Ayele $^{1 *}$, Habtemu Jarso ${ }^{2}$ and Girma Mamo ${ }^{1}$

\begin{abstract}
Background: Tenofovir (TDF) based regimen was reported to have better immunological outcomes. Unfortunately, there is limited information regarding the immunologic outcome associated with this regimen in Ethiopia, as its routine utilization in this setting begun since 2013.

Methods: A 2 years retrospective cohort study was conducted at Jimma University Specialized Hospital, 346 km Southwest of Addis Ababa, Ethiopia. A total of 280 patients' data from September 2012 to July 2014 was extracted from records from February 10, 2015 to March 10, 2015. Records were selected using a simple random sampling technique. Data on socio-demographic, clinical and drug related variables were collected; entered into EpiData 3.1 and analyzed by STATA 13.1. Mixed effect linear regression was performed to assess difference in CD4+ change between groups adjusting for baseline characteristics. The change in predicted CD4 count attributed to each regimen was also assessed by marginal analysis. $P<0.05$ for slopes of the random effect linear regression was used as indicators for presence of association.

Results: The mean (SD) duration of cohort follow up was 714.2 (69.6) and 708.8 (78.9) days ( $P=0.753$ ) for TDF and AZT groups respectively. The minimum follow up duration was 7.4 and 8.9 months for TDF and AZT groups respectively. Most of TDF (93.6\%) and AZT (91.4\%) groups completed their follow up, 5 (3.6\%) TDF and 6 (4.3\%) AZT groups died and 4 (2.9\%) TDF and 6 (4.3\%) AZT groups were lost for follow-up $(P=0.769)$. There was statistically significant difference in immunologic recovery between the groups $(B=+34.08,95 \% \mathrm{Cl}[7.8,60.35], P=0.027)$ over time. The predicted CD4+ count for TDF/3TC/EFV was $\left(B=+347.65\right.$ cells $\left./ \mathrm{mm}^{3}, \mathrm{P}<0.001\right)$ whereas that of AZT/3TC/EFV was $\left(\mathrm{B}=+281.54\right.$ cells $\left./ \mathrm{mm}^{3}, \mathrm{P}<0.001\right)$.
\end{abstract}

Conclusions: TDF based regimens have shown more efficacy compared to AZT based regimens though AZT based regimens are more affordable in low income countries like Ethiopia. However, we recommend further study with quality design to assess the prevalence of sub-optimal CD4+ response (net CD4 gain $<50$ cells/ $\mu \mathrm{l} / 6 \mathrm{month}$ ) in this set-up among TDF users.

Keywords: Immunological outcomes, Tenofovir regimen, Zidovudine regimen, Ethiopia

\section{Background}

Around 1980s, Acquired immunodeficiency syndrome (AIDS) was globally emerged as a major public health

\footnotetext{
*Correspondence: teshale@mtu.edu.et; tesh.ayu2016@gmail.com 1 Department of Pharmacy, Jimma University Medical Centre, Institute of Health, Jimma University, Jimma, Ethiopia
}

Full list of author information is available at the end of the article threat. The reaction against it has led to unprecedented attention and commitment from the international community to improve access to human immune virus(HIV) care, antiretroviral treatment (ART) and prevention $[1,2]$. The introduction of potent ART has dramatically reduced HIV/AIDS associated crisis-reduced rates of mortality and morbidity, improved quality of life, 
revitalized communities and transformed perceptions on the disease from a plague to a manageable chronic illness [3-6].

Currently, there are more than 20 ARV compounds approved for use in United States (US) and Europe. Multiple adult HIV treatment guidelines recommend the nucleos $(\mathrm{t})$ ide reverse transcriptase inhibitors; AZT or TDF based regimens and most are in favour of TDF based regimens as the safer regimen for patients with no contraindication due to its proven effectiveness, favourable toxicity profile, and demonstrated regimen durability $[1,7-9]$.

Safe and efficacious ART regimens improve patient care through rapidly restoring the immune cells, promoting adherence and alleviating the hazards of mortality [ 1 , $10,11]$. TDF is one of the ART drugs that come to be routinely utilized in Ethiopia since the past 2 years. For this drug, the recent WHO report indicated that data on the risk of major clinical events such as mortality, renal failure and, bone fractures were limited, and particularly for our setups there is no immunologic finding as well [11].

Studies from developed regions showed that there were 18.0 and $18.8 \%$ immunologic failures in the EFV/FTC/ TDF and EFV/3TC/AZT arms, respectively. There were no significant differences in the risk of HIV-1 disease progression or death [12]. In other findings, TDF based regimens has demonstrated a better immunologic outcome only when combined with Efavirenz as compared to AZT based preparations [3, 13, 14]. In contrary, a finding from south Africa concludes that, in population of HIV patients on treatment in resource-limited settings AZT-containing regimens appear to show a slightly protective than TDF-based regimens [15]. Despite, this evidence variation, its immunologic benefits unknown in an Ethiopian setting where patients generally present late, have high rates of $\mathrm{TB}$ and other infectious conditions [16]. Hence further investigation, particularly in health setups of the current setting, was warranted. Therefore, this study was aimed to provide additional information by making a head to head comparison of the two regimens in terms of immunologic benefits and associated risk factors in a teaching hospital of Ethiopia, one of the resource constrained settings.

\section{Methods}

\section{Study area and period}

The study was conducted at Jimma University specialized Hospital which is located in Jimma town; Jimma Zone, $346 \mathrm{~km}$ Southwest of Addis Ababa, Ethiopia. The hospital has separate ART clinic with about 7486 clients. The ART clinic provides HIV and TB treatment and care. Patient data from September 2012 to July 2014 was extracted from records from February 10, 2015 to March 10, 2015.

\section{Study design and population}

A retrospective hospital based cohort study was conducted on adult patients who were on TDF and AZT based regimens and fulfilled inclusion criteria. The study was conducted by dividing the total sample into two groups: TDF and AZT groups.

\section{Inclusion and exclusion criteria}

We included patients who were older than 14 years, have at least 6 months follow-up, whose records were legible and complete, and who have at least baseline and sixth month CD4 count. We excluded pregnant women from the study because there is significant pharmacokinetic change that is enough to impact the treatment outcome in this group of population. Those whose regimen was changed were also excluded from the study.

\section{Sample size and sampling techniques}

Sample size determination was guided by the number of patients on TDF/3TC/NVP where only 70 patients fulfilled the inclusion criteria. Patients from other regimens were selected based on the size of this group to satisfy 1:1 ratio of AZT to TDF group. Therefore, frequency matching was used to select a total of 280 subjects (140 TDF group and 140 AZT group). Records were selected by simple random sampling technique using computer generated random numbers.

\section{Data collection}

Data on demographic, clinical, laboratory, drug administered, comorbidities and adherence were collected by record review using English version checklist which was prepared after reviewing different relevant literatures. Baseline body mass-index of the subjects was calculated after collection of baseline height and weight of the patient from patients chart. Data from antiretroviral drugs sheet and patient information sheet were collected by pharmacists, while nurses collected data from ART intake and follow up forms.

\section{Data processing and analysis}

Data were double entered into Epi-Data 3.1 and exported to STATA 13.1 for cleaning and analysis. Descriptive analyses were performed and results were presented by text, tables and charts. Bi-variate and multivariable mixed effect linear regression for repeated measurements were performed to assess adjusted effect of the ART regimen and identify additional predictors of CD4 recovery. Coefficient of mean CD4 count with 95\% confidence intervals was used as measure of strength of association and $\mathrm{P}<0.05$ was considered to declare a statistical significance. Marginal analysis was also conducted to see the difference among specific regimen category. 


\section{Results}

A total of 1034 patients were on antiretroviral therapy (ART) for at least 6 months during the study period. Nine hundred eighty six had complete CD4+ count at 6 month of treatment. Fourteen records were used for pre-test, 22 and 110 records were excluded because of pregnancy and regimen change respectively. Only 70 patients remained on TDF/3TC/NVP and this governed the sample selection (Fig. 1).

The cohort was followed for 2 years. The overall time the cohort was at risk was 539.39 years. The cohort contributed to a total of 2.74/100 and 2.72/100 person-years of followup for TDF and AZT groups respectively. The mean (SD) duration of follow up was 714.2 (69.6) and 708.8 (78.9) days
$(P=0.753)$ for TDF and AZT groups respectively. The minimum follow up duration was 7.4 and 8.9 months for TDF and AZT groups respectively. Most of TDF (93.6\%) and AZT (91.4\%) groups completed their follow up, 5 (3.6\%) TDF and 6 (4.3\%) AZT groups died and 4 (2.9\%) TDF and 6 (4.3\%) AZT groups were lost for follow-up $(P=0.769)$.

\section{Baseline socio-demographic and behavioural characteristics}

Majority of TDF (64.3\%) and AZT (66.4\%) groups were females. Majority of TDF (77.1\%) and AZT (85.9\%) groups were in the age group 25-45 years with mean (SD) of $32.3(7.4)$ and $32.3(9.2)$ years respectively. Majority of TDF (62.9\%) and AZT (73.6\%) groups had BMI $\geq 18 \mathrm{~kg} /$

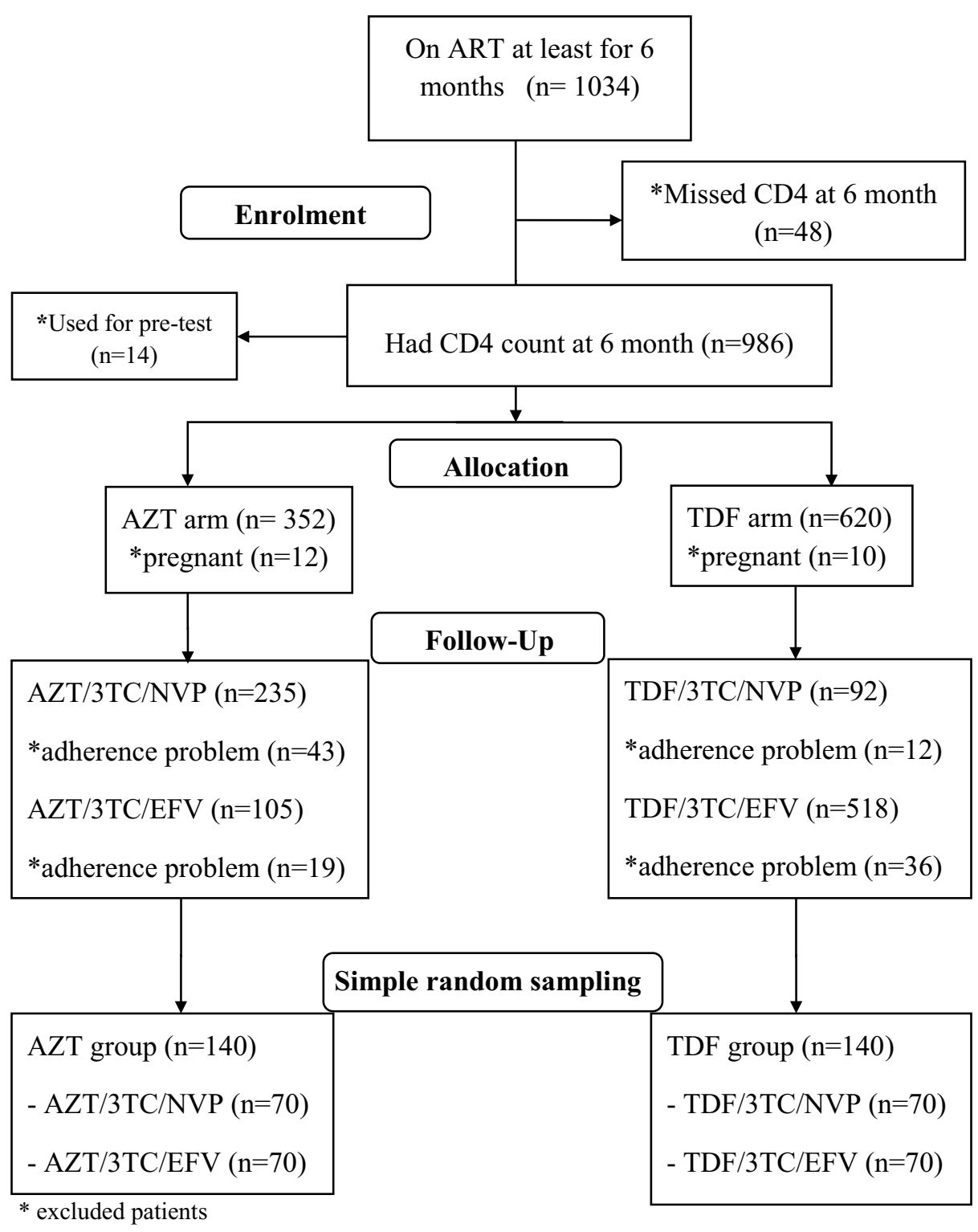

Fig. 1 Sample recruitment diagram from cohort of patients on ART for at least 6 months at JUSH, September, 2012 to July, 2014 
$\mathrm{m}^{2}$ with mean (SD) of 19.7 (3.4) and 20.4 (3.0) respectively. Larger proportion of TDF (48.6\%) and AZT (41.5\%) groups were employed. Majority of TDF (69.3\% and AZT (78.5\%) groups were urban. Concerning alcohol use, most of TDF (80.7\%) and AZT (72.9\%) groups had history of alcohol use. Regarding between groups comparison of distribution of baseline socio-demographic and behavioural characteristics of patients, there was statistically significant difference between groups only in terms of religion (Table 1).

\section{Baseline clinical characteristics}

Majority of TDF (65.7\%) and AZT (53.9\%) groups had baseline CD $4+$ count $<200$ cells $/ \mathrm{mm}^{3}$ with mean (SD) of 164.64 (83.36) and 175.21 (89.14) respectively. There was statistically significant difference between groups in terms of baseline CD4 count. Leading percentage $(33.6 \%)$ both TDF and AZT groups were in WHO clinical stage III and II respectively. Most of TDF (78.6\%) and majority of AZT (56.4\%) groups had working functional status and there was statistically significant difference between groups. Twenty $(15.3 \%)$ and $17(12.1 \%)$ of patients were treated for TB from TDF and AZT groups respectively. CPT was prescribed for most of (87.9\%) and nearly all of (92.14\%) patients in TDF and AZT groups respectively, whereas INH was prescribed for only 26.4 and $21.5 \%$ of patients in TDF and AZT groups respectively (Table 2).

\section{Immunologic outcome (CD4+ change)}

The mean change in CD4+ over study period is shown by Fig. 2. The overall mean (SD) CD4+ has shown greater improvement among TDF [321.7 (164.8)] than AZT group [299.4 (126.1)]. If each regimen is considered separately, the maximum and minimum mean $\mathrm{CD} 4+$ count gain at any given time was attained by TDF/3TC/EFV and AZT/3TC/EFV groups respectively (Fig. 2).

At 6 month, the overall proportion of sub-optimal $\mathrm{CD} 4+$ response (net $\mathrm{CD} 4+$ gain $<50$ cells/ $\mu \mathrm{l}$ ) was $23.95 \%$ (30\% TDF/EFV, $28.3 \% \mathrm{AZT} / \mathrm{EFV}$, and $23.8 \% \mathrm{TDF} / \mathrm{NVP}$ ). Earlier at the initiation of ART, the CD4+ count showed a linear trend but it becomes more flat after 18th month with a very minimal gain irrespective of the regimen.

\section{Predictors of $\mathrm{CD} 4+$ change}

Considering consecutive CD4+ count as an outcome variable, multilevel mixed effect linear regression was performed (Table 3). The slope of random-effect multiple linear regression was used to interpret the overtime change in CD4+ count attributed to the predictor variables.
Table 1 Socio-demographic and behavioural characteristics for cohort of patients on ART for a least 6 months at JUSH, September 2012 to July 2014

\begin{tabular}{|c|c|c|c|}
\hline \multirow{2}{*}{$\begin{array}{l}\text { Baseline socio-demo- } \\
\text { graphic and behavioural } \\
\text { characteristics }\end{array}$} & \multicolumn{2}{|l|}{ Group } & \multirow[t]{2}{*}{ P value } \\
\hline & $\begin{array}{l}\text { TDF group } \\
\text { no (\%) }\end{array}$ & $\begin{array}{l}\text { AZT group } \\
\text { no }(\%)\end{array}$ & \\
\hline \multicolumn{4}{|l|}{ Sex } \\
\hline Male & $50(35.7)$ & 47 (33.6) & 0.706 \\
\hline Female & $90(64.3)$ & $93(66.4)$ & \\
\hline \multicolumn{4}{|l|}{ Age } \\
\hline$<25$ & $27(19.3)$ & $32(25.9)$ & 0.276 \\
\hline $25-45$ & $108(77.1)$ & $98(85.9)$ & \\
\hline$>45$ & $5(3.6)$ & $10(7.2)$ & \\
\hline Mean (SD) & $32.3(7.4)$ & $32.3(9.2)$ & $0.977^{* *}$ \\
\hline \multicolumn{4}{|l|}{ BMI } \\
\hline$<18.5$ & $52(37.1)$ & $37(26.4)$ & 0.130 \\
\hline$\geq 18.5$ & $88(62.9)$ & $93(73.6)$ & \\
\hline Mean (SD) & $19.7(3.4)$ & $20.4(3.0)$ & $0.062^{* *}$ \\
\hline \multicolumn{4}{|l|}{ Educational level } \\
\hline Illiterate & $22(15.8)$ & $30(21.4)$ & \\
\hline Primary & $48(34.2)$ & $58(41.4)$ & 0.089 \\
\hline Post-primary & $70(50)$ & $52(37.2)$ & \\
\hline \multicolumn{4}{|l|}{ Residence } \\
\hline Urban & $97(69.3)$ & $110(78.5)$ & 0.077 \\
\hline Rural & $43(30.7)$ & $30(21.5)$ & \\
\hline \multicolumn{4}{|l|}{ Occupation } \\
\hline Employed & 68 (48.6) & $58(41.5)$ & \\
\hline Unemployed & $46(22.8)$ & $55(39.2)$ & 0.446 \\
\hline Housewife & 26 (18.6) & $27(19.3)$ & \\
\hline \multicolumn{4}{|l|}{ Religion } \\
\hline Orthodox & $59(42.1)$ & $80(57.1)$ & \\
\hline Muslim & $45(32.1)$ & $42(30)$ & $0.010^{*}$ \\
\hline Others & $36(25.8)$ & 18 (12.9) & \\
\hline \multicolumn{4}{|l|}{ Marital status } \\
\hline Married & $76(54.3)$ & $77(55.0)$ & \\
\hline Single & 23 (16.5) & $29(20.7)$ & 0.207 \\
\hline Divorced & $33(23.5)$ & $21(15.1)$ & \\
\hline Widowed & $8(5.7)$ & $13(9.2)$ & \\
\hline \multicolumn{4}{|l|}{ Alcohol use } \\
\hline Yes & 113 (80.7) & 102 (72.9) & \\
\hline No & $27(19.3)$ & $38(27.1)$ & 0.120 \\
\hline
\end{tabular}

* Statistically significant at $P$ value 0.05 cut off point

** T test

Accordingly, the average gain in CD4+ count achieved at every visit among the cohort was 38 cells $/ \mathrm{mm}^{3}$ (B $=38.18,95 \%$ CI $[33.11,43.24], \mathrm{P}<0.001)$ with the conditional correlation coefficient of $64.9 \%$, i.e. $64.9 \%$ of the variability in CD4+ count between two visits was explained by unobserved patient specific factors. Among these, $38.99 \%$ of the variation in $\mathrm{CD} 4+$ change was 
Table 2 Baseline and on follow up clinical characteristics for cohort of patients on ART for a least 6 months at JUSH, September 2012 to July 2014

\begin{tabular}{lccc}
\hline $\begin{array}{l}\text { Clinical } \\
\text { characteristics }\end{array}$ & TDF group no (\%) & AZT group no (\%) & P value \\
\hline $\begin{array}{l}\text { Baseline CD4+ count } \\
<200\end{array}$ & $92(65.7)$ & $74(53.9)$ & $0.029^{*}$ \\
$\geq 200$ & $48(34.3)$ & $66(47.1)$ & \\
Mean (SD) & $164.64(83.36)$ & $175.21(89.14)$ & $0.307^{* *}$ \\
Baseline WHO clinical stage & & \\
I & $32(22.9)$ & $36(25.7)$ & \\
II & $46(32.9)$ & $47(33.6)$ & 0.928 \\
III & $47(33.6)$ & $43(30.7)$ & \\
IV & $15(10.6)$ & $14(10)$ & \\
Baseline functional status & & & \\
W & $110(78.6)$ & $79(56.4)$ & \\
A & $24(17.1)$ & $56(40.0)$ & $0.000^{*}$ \\
B & $6(4.3)$ & $5(3.6)$ & \\
TB Treatment & & & \\
No & $120(84.7)$ & $113(87.9)$ & 0.773 \\
Yes & $20(15.3)$ & $17(12.1)$ & \\
Prophylaxis & & & \\
CPT+ INH & $37(26.4)$ & $30(21.5)$ & \\
CPT alone & $86(61.4)$ & $99(70.7)$ & 0.231 \\
Neither & $17(12.2)$ & $11(7.8)$ & \\
\hline
\end{tabular}

* Statistically significant at $P$ value 0.05 cut off point ** T test

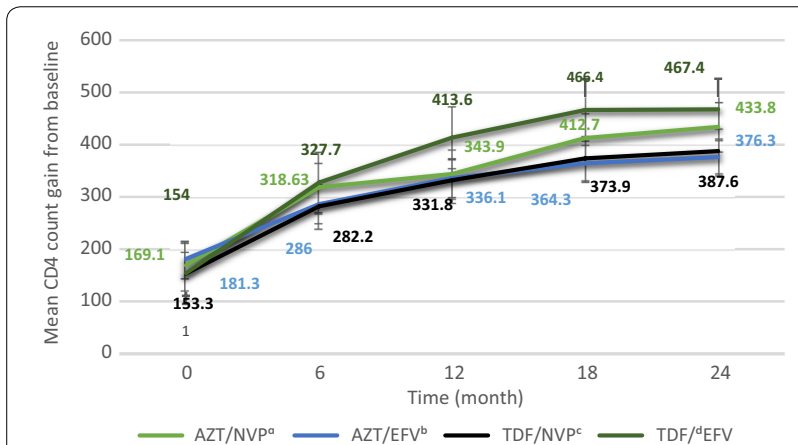

Fig. 2 Average gain in CD4+ count taken every 6 month for a cohort of patients on ART for at least 6 months at JUSH, September, 2012 to July, 2014. Missing values per each regimen at 12,18 and 24 months respectively: ${ }^{a}(2,7,11) ;{ }^{b}(11,3,2){ }^{c}(7,1,9) ;{ }^{d}(5,12,4)$

explained by differences in the regimens where as $25.34 \%$ of the variation is attributed to other regression variables $(\mathrm{P}<0.001)$, showing an important heterogeneity between patient groups.

In the overall analysis, keeping other factors constant, older age was found to be one of the negative predictors of CD4+ count change. So younger patients (age $<25$ years) were found to have +66 gain in $\mathrm{CD} 4+$ count every 6 months as compared to those aged $\geq 45$ years $(\mathrm{B}=-66.19$ 95\% CI [-126.68, -5.70], P $=0.032$ ).

Among the predictor variables, female sex was strongly associated with progressive CD4+ count gain at each visit. So, females had +39 CD4+ cells advantage over time $(\mathrm{B}=33.86,95 \% \mathrm{CI}[33.11,43.24], \mathrm{P}=0.013)$ as compared to males. Patients with BMI $\geq 18.5 \mathrm{~kg} / \mathrm{m}^{2}$ had a significantly higher CD4 + change $\left(+32 \mathrm{cell} / \mathrm{mm}^{3}\right)$ over time than those who had BMI $<18.5 \mathrm{~kg} / \mathrm{m}^{2}(\mathrm{~B}=-32$, 95\% CI [-60.16, -4.27], $\mathrm{P}=0.011$ ).

Baseline CD4+ count was also another independent predictor for $\mathrm{CD} 4+$ advantage over time $(\beta=0.879,95 \%$ CI $[0.70,1.06], \mathrm{P}<0.001)$. More importantly, patients in TDF group had a significant CD4+ count gain per visit compared with their AZT counterparts $(B=34.08,95 \%$ CI [7.80, 60.35], $\mathrm{P}=0.027$ ).

In this study, other baseline patient factors such as WHO clinical stage, TB treatment, educational status, place of residence, religion, occupational status, marital status, alcoholic use and prophylaxis had no significant association with $\mathrm{CD} 4+$ change.

\section{Marginal analysis}

To predict the expected change in CD4+ count in both groups at the end of treatment period, post-estimation marginal analysis was conducted.

In TDF group, the predicted mean $\mathrm{CD} 4+$ count changes were 347.65 and 295.73 cells $/ \mathrm{mm}^{3}$ for patients treated with TDF/3TC/EFV and TDF/3TC/NVP respectively. In AZT group, the predicted mean CD4+ count changes were 319.11 and 281.54 cells $/ \mathrm{mm}^{3}$ for patients treated with $\mathrm{AZT} / 3 \mathrm{TC} / \mathrm{NVP}$ and AZT/3TC/EFV respectively. These figures were exactly the expected increase in CD4+ count associated with each regimen and has a crucial clinical implication in guiding clinicians to choose which regimen to initiate on as the role of good immunologic recovery in treatment of HIV infection is multidimensional. So, this section of analysis (Table 4) clearly showed that the overall outcome was better in TDF than AZT group.

\section{Discussion}

Analysis of every 6 month mean CD4+ gain showed that the maximum gain in mean $\mathrm{CD} 4+$ count was attained by TDF/3TC/EFV followed by AZT/3TC/NVP and $\mathrm{TDF} / 3 \mathrm{TC} / \mathrm{EFV}$ at any given time in the course of therapy. $\mathrm{AZT} / 3 \mathrm{TC} / \mathrm{EFV}$ had the least immunologic recovery over the entire treatment course. The CD4+ count showed a linear trend but became more flat after 18th month with a very minimal gain irrespective of the regimen. The overall prevalence of sub-optimal CD4+ response was found to be 67 (23.95\%). At first 6 months, majority of sub-optimal immunologic responders belonged 
Table 3 Random-effect linear regression analysis of trend of CD4+ count (slope, cells $/ \mathrm{mm}^{3} / 6 \mathrm{month}$ ) at JUSH, September 2012 to July 2014

\begin{tabular}{|c|c|c|c|c|}
\hline \multirow[t]{2}{*}{ Variable } & \multicolumn{2}{|l|}{ Unadjusted } & \multicolumn{2}{|l|}{ Adjusted } \\
\hline & $\mathrm{B}[95 \% \mathrm{Cl}]$ & $P$ value & $\mathrm{B}[95 \% \mathrm{Cl}]$ & $P$ value \\
\hline \multicolumn{5}{|l|}{ Sex } \\
\hline Male & 0 & & 0 & \\
\hline Female & $52.373[21.22,84.24]$ & 0.001 & $33.86[33.11,43.24]$ & 0.013 \\
\hline \multicolumn{5}{|l|}{ Age } \\
\hline$<25$ & 0 & & 0 & \\
\hline $25-45$ & $-53.15[-90.03,-16.27]$ & 0.005 & $-27.32[-59.3,4.66]$ & 0.094 \\
\hline$>45$ & $-120.87[-191.24,-50.49]$ & 0.001 & $-66.19[-126.68,-5.70]$ & 0.032 \\
\hline \multicolumn{5}{|l|}{ BMI } \\
\hline$<18.5$ & $-48.08[-80.42,-15.74]$ & 0.004 & $-32.77[-60.16,-4.27]$ & 0.011 \\
\hline$\geq 18.5$ & 0 & & 0 & \\
\hline \multicolumn{5}{|l|}{ Educ. level } \\
\hline Illiterate & $-0.5[-42.86,41.86]$ & 0.982 & & \\
\hline Primary & $14.42[-19.59,48.44]$ & 0.406 & & \\
\hline Post-primary & 0 & & & \\
\hline \multicolumn{5}{|l|}{ Residence } \\
\hline Urban & 0 & & & \\
\hline Rural & $-12.35[-47.18,22.54]$ & 0.488 & & \\
\hline \multicolumn{5}{|l|}{ Occupation } \\
\hline Employed & 0 & 0.936 & 0 & 0.796 \\
\hline Unemployed & $-1.40[-32.23,32.44]$ & 0.015 & $3.96[-26.04,33.95]$ & 0.293 \\
\hline House wife & $51.50[10.2,92.80]$ & & $21.35[-18.42,61.12]$ & \\
\hline \multicolumn{5}{|l|}{ Marital status } \\
\hline Single & $30.25[-11.18,71.68]$ & 0.152 & $40.45[0.52,80.37]$ & 0.069 \\
\hline Married & 0 & 0.525 & 0 & \\
\hline Divorced & $13.06[-27.17,53.29]$ & 0.513 & $6.42[-32.27,45.11]$ & 0.745 \\
\hline Widowed & $-19.89[-79.56,39.77]$ & & $-2.33[-55.27,50.6]$ & 0.931 \\
\hline \multicolumn{5}{|l|}{ Religion } \\
\hline Orthodox & 0 & & 0 & \\
\hline Muslim & $22.91[-12.00,57.83]$ & 0.198 & $20.83[-8.86,50.53]$ & 0.166 \\
\hline Other & $0.21[-40.70,41.13]$ & 0.992 & $-12.09[-46.89,22.71]$ & 0.496 \\
\hline \multicolumn{5}{|l|}{ Alcohol } \\
\hline Yes & $-26.1[-62.15,9.94]$ & 0.156 & $8.48[-22.88,39.83]$ & 0.596 \\
\hline No & 0 & & 0 & \\
\hline \multicolumn{5}{|l|}{ ART regimen } \\
\hline TDF & $11.58[-18.98,42.15]$ & 0.458 & $34.08[7.80,60.35]$ & 0.027 \\
\hline AZT & 0 & & 0 & \\
\hline Baseline CD4+ count & $0.97[0.80,1.15]$ & 0.000 & $0.879[0.70,1.06]$ & 0.000 \\
\hline \multicolumn{5}{|l|}{ WHO stage } \\
\hline । & 0 & & & \\
\hline$\|$ & $-16.76[-57.59,24.06]$ & 0.421 & & \\
\hline III & $-23.17[-64.32,17.97]$ & 0.270 & & \\
\hline IV & $-29.27[-86.35,27.81]$ & 0.315 & & \\
\hline \multicolumn{5}{|l|}{ TB (treatment) } \\
\hline No & 0 & & 0 & \\
\hline Yes & $-48.18[-85.37,5.00]$ & 0.081 & $-20.74[-59.05,17.57]$ & 0.289 \\
\hline \multicolumn{5}{|l|}{ Prophylaxis } \\
\hline $\mathrm{CPT}+\mathrm{INH}$ & 0 & & 0 & \\
\hline CPT alone & $-29.40[-65.65,6.85]$ & 0.112 & $-10.34[-40.57,19.88]$ & 0.502 \\
\hline Neither & $-40.89[-97.93,16.16]$ & 0.160 & $-22.3[-70.33,25.73]$ & 0.363 \\
\hline
\end{tabular}


to TDF/3TC/EFV (30\%) and lowest proportion of suboptimal immunologic responder was observed among AZT/3TC/EFV (17.9\%).

Our finding of mean CD4+ recovery was in agreement with a randomized multi-centre open-label study by Gallant et al. [9], where a maximum immunologic response was achieved by TDF/3TC/EFV $\left(270\right.$ cells $\left./ \mathrm{mm}^{3}\right)$ followed by AZT/3TC/EFV $\left(237\right.$ cells $\left./ \mathrm{mm}^{3}\right)$ at 96 weeks. Another finding from Nigeria indicated that TDF/3TC/NVP is much more inferior $\left(208\right.$ cells $\left./ \mathrm{mm}^{3}\right)$ to AZT/3TC/NVP $\left(221.1\right.$ cells $\left./ \mathrm{mm}^{3}\right)$ at 12 months of therapy [17]. The difference in the outcome when TDF/3TC is combined with EFV and NVP may be due to negative pharmacokinetic or pharmacodynamics interaction between this NRTI backbone and NVP. The finding from the marginal analysis also indicated that change in mean CD4+ count is significantly higher in TDF based EFV regimen.

The bi-phasic CD4+ count response shown in our finding was also reported by other findings $[18,19]$ as a rapid increase of memory CD4+ cells (a high CD4+ count slope) in the first several months after treatment initiation succeeded by a slow increase in naive CD4+ cells (smaller slope compared to the initial several months). The linear trend in CD4+ increment at early phase of of therapy became flat with minimal $\mathrm{CD} 4+$ gain latter after 18th month of treatment irrespective of the regimen used. So "when will target CD4+ count (500-800 cells/ $\mathrm{mm}^{3}$ ) be attained after initiation of ART?" is the question to be addressed by further study.

Immunologic response after 6 months of ART indicates a favourable clinical outcome in HIV-1 infected patients regardless of virologic response [20]. Several studies has reported that as many as $8-40 \%$ of patients on ART do not show a significant increase in CD4+ cell count despite viral suppression $[18,21,22]$. Our finding, in general, is almost consistent with these studies.

To these days, studies are unable to justify the impact of ART regimen on sub-optimal immunologic recovery. So, it is not surprising that most of these patients in this study were from TDF based regimens. As the recovery of the CD4+ T-cell count is hindered by several patient and viral factors, including: residual viral replication, impaired thymic function, advanced age, enhanced T-cell activation and apoptosis, genetic variations, baseline anaemia and poor adherence [18, 21, 23, 24], our finding might not quest the efficacy of TDF based regimens in resource limited settings, even though it needs a further workup with adequately powered and methodological high quality study.

Study by Mauro et al. [25] has confirmed older age as a key independent predictor for sub-optimal immunologic response as thymus activity decreases with age [26]. This finding agreed with our result where older age was statistically significant negative predictor of CD4+ gain on multiple regression.

The pre-treatment $\mathrm{CD} 4+$ count in relation to suboptimal immunologic response, however, is controversial as some literatures favour higher baseline CD4+ $(>200$ cells $/ \mathrm{mm}^{3}$ ) [26] and explained it as "starting treatment at higher $\mathrm{CD} 4+$ cell counts limits the scope for further increases". Other literatures favoured lower baseline CD4+ count $\left(<200\right.$ cells $\left./ \mathrm{mm}^{3}\right)$ and this is biologically plausible given that a low nadir pre-treatment CD4+ cell count is thought to be suggestive of more extensive depletion of CD4+ cells in the gut-associated lymphoid tissue during acute HIV infection, and may be delayed or refractory to reconstitution with ART [27].

As this study has short comings including absence of viral marker measurement to conclude the rate of suboptimal immunologic recovery among the patients, further study with quality design is needed as lack of knowledge about this subgroup may contribute to inadequate clinical management and current HIV treatment guidelines do not provide specific applicable guidance [18].

The overall random effect linear regression analysis had pointed out that, baseline BMI, sex, age, baseline CD4+ count, and exposure to TDF based regimen were independent predictors for $\mathrm{CD} 4+$ change over time. The marginal effects of each regimens confirmed that the immunologic outcome associated with TDF based EFV preparations was more convincing and made it the golden regimen to be utilized in this

Table 4 The predicted mean CD4+ change of patients treated with AZT and TDF based regimens at JUSH, September 2012 to July 2014

\begin{tabular}{|c|c|c|c|c|c|c|}
\hline \multirow[t]{2}{*}{ Status } & \multirow[t]{2}{*}{ Status } & \multicolumn{2}{|c|}{ Delta-method } & \multirow[t]{2}{*}{$\mathrm{t}$} & \multirow[t]{2}{*}[95\%\mathrm{Cl}]{} & \multirow[t]{2}{*}{$P$ value } \\
\hline & & Margins & Standard error & & & \\
\hline \multirow[t]{2}{*}{ Unexposed } & AZT3TC/NVP & 319.11 & 19.34 & 16.50 & $281.02,357.20$ & $P<0.001$ \\
\hline & AZT/3TC/EFV & 281.54 & 18.39 & 15.31 & $245.31,317.77$ & $P<0.001$ \\
\hline \multirow[t]{2}{*}{ Exposed } & TDF/3TC/NVP & 295.73 & 18.39 & 16.08 & $259.50,331.96$ & $P<0.001$ \\
\hline & TDF/3TC/EFV & 347.65 & 18.39 & 18.90 & $311.42,383.89$ & $P<0.001$ \\
\hline
\end{tabular}


setup (margins $=347.65$ cells $/ \mathrm{mm}^{3} /, P<0.001$ ) followed by AZT/3TC/NVP $\left(\mathrm{m}=319.11\right.$ cells $/ \mathrm{mm}^{3}$, $P<0.001)$ and TDF/3TC/NVP $(\mathrm{m}=295.73, \mathrm{P}<0.001)$. However, AZT/3TC/EFV had lowest predicted change in CD4+ count $(\mathrm{m}=281.54, \mathrm{P}<0.001)$. This implies that this regimen has minimal immunologic response and its clinical utilization need to be reconsidered.

Females had greater CD4+ improvement over time. Accordingly, every visit of female patients was associated with the average CD4+ count of 39 cells $/ \mathrm{mm}^{3}(\beta=33.86$ [33.11, 43.24], $P=0.013)$. Similar study from Lao Democratic Republic strengthen this finding [28]. But it was inconsistent with study from Asia [19] probably due to differences in study setup and sample size (1676 versus 280 ), where females contribute only $26 \%$ of the sample analysed.

The impact of age on immunologic recovery was well described [26] and this study had found concordance with previous findings. Accordingly, the $\mathrm{CD} 4+$ gain attained by younger $(<25$ years) patients was +66 cells/ $\mathrm{mm}^{3}$ as compared to those older than 45 years of age $(\beta=-66.19,95 \%$ CI $[-126.68,-5.70], P=0.032)$. The finding is consistent with the studies from Asia [19] and Ghana [29] and which reported the inverse relationship between age and CD4+ gain. This is mainly due to failure of cellular expansion or non-sustained cell survival in the periphery or age related central degeneration of thymus function as patients become older [18].

In the cohort, those with BMI $\geq 18.5 \mathrm{~kg} / \mathrm{m}^{2}$ had a better immunologic outcome and each visit was associated with 32 cells $/ \mathrm{mm}^{3}$ of $\mathrm{CD} 4+$ count advantage as compared to patients with BMI $<18.5 \mathrm{~kg} / \mathrm{m}^{2}(\beta=-32.22$, $95 \%$ CI $[17.23,51.85], \mathrm{P}<0.001)$. This is concurrent with the study by Bastard et al. [ [28].] in which BMI $>18 \mathrm{~kg} /$ $\mathrm{m}^{2}$ was reported to have a protective effect for CD4 count increment at 9 months of therapy ( $\mathrm{HR}=0.39,95 \%$ CI $0.25-0.60$ ). This implies that higher BMI is a sign of good nutritional status and it is fertile ground for better immunologic revival.

The baseline $\mathrm{CD} 4+$ count was another positive predictor for successful immunologic revival. So, a patient has a $0.879 \mathrm{CD} 4+$ cell count advantage over time, for every count higher in initial CD4+ count, when compared to his/her counterpart $(B=0.87995 \%$ CI $[0.70$, 1.06], $P<0.001)$. This finding is consistent form study by Lawrence et al. [27] and Mustapha et al. [29] in which higher baseline CD4+ count was associated with good immunologic outcome. This might be due to less extensively depleted immune system will be boosted easily after initiation of ART. The overall clinical and immunological findings were suggestive of better outcome of ART if initiated at higher CD4+ count. This finding also agrees with the recent WHO ART guidelines [30] which described the initiation of ART irrespective of WHO stage and CD4+ count in adolescents and adults.

In contrary, the finding disagrees with some studies showing poor immunologic recovery including discordant responders when ART was commenced at higher CD4+ count [31]. This may be due to the goal CD4+ in HIV patients $\left(500\right.$ cells $/ \mathrm{mm}^{3}$ ) [32] can be attained immediately in those with higher baseline CD4+ and further increment could be impossible. The reason for the deviation might be due to differences in sample size and setup. The multicenterity of the previous study might also contribute for the difference.

From this study, patients randomized to TDF group had a significant $C D 4+$ count advantage per visit relative to patients randomized to AZT group ( $B=+34.08,95 \%$ $\mathrm{CI}[7.80,60.35], \mathrm{P}=0.001)$. This study is consistent with most of the previous findings that described TDF based regimens with better immunologic outcome $[9,14,31$, 32].

\section{Conclusions}

The results of this study suggest that TDF based regimens especially, TDF/3TC/EFV had excellent immunologic recovery followed by AZT based NVP. Since aged patients, those with baseline CD4+ count $<200$ cells/ $\mathrm{mm}^{3}$ and patients with pre-treatment BMI $<18.5$ were poor immunologic responders, they need special attention while delivering care and treatment. However, the prevalence of sub-immunologic recovery among the TDF users in the resource constrained settings needs to be assessed further.

\section{Authors' contributions}

TA: conceived and led the conduct of study; acquisition of data, analysis and interpretation of data; and drafting of the manuscript. GM: assisted with the design and conduct of study; analysis and interpretation of data; and revision of manuscript for intellectual content. $\mathrm{HJ}$ : assisted with the design and conduct of study; analysis and interpretation of data; and revision of manuscript for intellectual content and reviewers' comments. All authors read and approved the final manuscript.

\section{Author details \\ ${ }^{1}$ Department of Pharmacy, Jimma University Medical Centre, Institute of Health, Jimma University, Jimma, Ethiopia. ${ }^{2}$ Department of Epidemiology, Public Health Faculty, Institute of Health, Jimma University, Jimma, Ethiopia.}

\section{Acknowledgements}

We would like to thank pharmacists, nurses and physicians at JUSH ART clinic for their indispensable cooperation during acquisition of data.

\section{Competing interests}

The authors declare that they have no competing interests.

\section{Availability of data and materials}

The data of this work could be available for third body only up non author request. 


\section{Ethical clearance}

The present study was approved by the Institutional Review Board of Institute of Health, Jimma University; Jimma, Ethiopia and the need for informed consent was waived because of the retrospective, anonymous nature of the study. During data collection, confidentiality was ensured and for this reason, name and address of the patient was not recorded in the data collection check list.

Received: 25 August 2016 Accepted: 12 January 2017

Published online: 01 February 2017

\section{References}

1. Tirfe ZM, Ahmed TA, Tedla NB, Debere MK, Alamdo AG. Immunological responses of HIV/AIDS patients treated with Nevirapine versus Efavirenz based highly active anti-retroviral therapy in Addis Ababa, Ethiopia. Retrosp Cohort Study. 2013;1508:1502-8.

2. Solomon SS, Ganesh AK, Mehta SH, Yepthomi T, Balaji K, Anand S, et al. Immunologic response among HIV-infected patients enrolled in a graduated cost-recovery programme of antiretroviral therapy delivery in Chennai, India. Indian J Med Res. 2013;6(137):1145-53.

3. Alemayehu L, GizatMollaKassie BAH. Comparative study of the effects of antiretroviral therapy (ART) on the CD4 cell count in the Jimma University specialized hospital. J Pharm Sci Innov. 2014;3(4):310-4.

4. Tang MW, Kanki PJ, Shafer RW. A review of the virological efficacy of the 4 World Health Organization-recommended tenofovir-containing regimens for initial hiv therapy. J Clin Infect Dis. 2012;54(15):862-75.

5. Ruan $Y$, Xing H, Wang $X$, Tang $H$, Wang Z, Liu H, et al. Virologic outcomes of first-line HAART and associated factors among Chinese patients with HIV in three sentinel antiretroviral treatment sites. Trop Med Int Health. 2010;15(11):4-10.

6. Albrecht D, Altfeld M, Behrens G, Bredeek UF, Buhk T, Dickinson L, et al. HIV medicine [Internet]. 2007. www.HIVMedicine.com.

7. Spaulding A, Gw R, Siegfried N. Tenofovir or zidovudine in three-drug combination therapy with one nucleoside reverse transcriptase inhibitor and one non-nucleoside reverse transcriptase inhibitor for initial treatment of HIV infection in antiretroviral-naïve individuals. Cochrane Database Rev 2010;10.

8. Chi BH, Mwango A, Giganti M, Mulenga LB, Tambatamba-chapula B, Reid SE, et al. Early clinical and programmatic outcomes with tenofovirbased antiretroviral therapy in Zambia. J Acquir Immune Defic Syndr. 2010;54(1):63-70

9. Pozniak AL, Gallant JE, Dejesus E, Arribas JR, Gazzard B, Campo RE, et al. Tenofovir disoproxil fumarate, emtricitabine, and efavirenz versus fixed-dose zidovudine/lattmivudine and efavirenzt in antiretroviral-naive patients virologic, immunologic, and morphologic changes-a 96-week analysis. J Acquir Immune Defic Syndr. 2006;43(5):535-40.

10. Leon Regensberg CW. Aid for AIDS Clinical Guidelines, South Africa; 2010. p. 52

11. World Health Organization. Monitoring for renal toxicity in people receiving tenofovir and on tenofovir toxicity and how it affects disabilityadjusted life-years and quality-adjusted life-years. Systematic review. Basel Univ Hospital, Switzerland; 2014. p. 1-19.

12. Campbell TB, Smeaton LM, Kumarasamy N, Flanigan T, Klingman KL, Firnhaber C, et al. Efficacy and safety of three antiretroviral regimens for initial treatment of HIV-1: a randomized clinical trial in diverse multinational settings. PLoS ONE. 2012;9(8):e1001290.

13. Arribas JR, Pozniak AL, Gallant JE, Dejesus E, Gazzard B, Campo RE, et al. Tenofovir disoproxil fumarate, emtricitabine, and efavirenz compared with zidovudine/lamivudine and efavirenz in treatment-naive patients 144-week analysis. J Acquir Immune Defic Syndr. 2008;47:74-8.

14. Gallant Joel E, DeJesus Edwin, Arribis José R, Pozniak Anton L, Gazzard Brian, Campo Rafael E, Biao Lu, McColl Damian, Chuck Steven, Enejosa Jeffrey, Toole JJ, Tenofovir DF. Emtricitabine, and efavirenz vs. zidovudine, lamivudine, and efavirenz for HIV. N Engl J Med. 2006;354(3):251-60.

15. Babafemi AA. Comparison of clinical and immunological responses to Zidovudine(AZT) and Tenofovir(TDF) containing ARV regimens in patients taking HAART at Roma health service area of Lesetho. J Acquir Immune Defic Syndr. 2010;45(7):8-11.
16. Survey in HIV drug resistance (HIVDR) early warning indicators (EWIs). HIVDR EWl; 2012

17. Scarsi K, Darin K, Rawizza H, Meloni S, Chang C, Olaitan R, Agbaji O, Gashau W, Murphy R, Kanki P. TDF-3TC-NVP is inferior to AZT-3TC-NVP in a large ART program in Nigeria. J Acquir Immune Defic Syndr. 2010;1:517-21.

18. Muzah BP, Takuva S, Maskew M. Risk factors for discordant immune response among HIV-infected patients initiating antiretroviral therapy: a retrospective cohort study. South Afr J HIV Med. 2012;13(4):168-72.

19. Zhou J, Sirisanthana T, Kiertiburanakul S, Chen YA, Han N, Lim PL. Trends in CD4 counts in HIV-infected patients with HIV viral load monitoring while on combination antiretroviral treatment : results from The TREAT Asia HIV Observational Database. BMC Infect Dis. 2010;10(1):361.

20. Leport C, Grabar S, Lemoing V, Goujard C, Kazatchkine MD, Costagliola D, Weiss L. Clinical outcome of patients with HIV-1 infection according to immunologic and virologic response after. Ann Int Med. 2000;133(6):401-10.

21. Nakanjako D, Kiragga A, Ibrahim F, Castelnuovo B, Kamya MR, Easterbrook PJ. Sub-optimal CD4 reconstitution despite viral suppression in an urban cohort on antiretroviral therapy (ART) in sub-Saharan Africa: frequency and clinical significance. AIDS Res Ther. 2008:5(23):1-9.

22. Casotti JA, Passos LN, Oliveira FJ, Cerutti C. Luciana Neves FJP de O\& CCJ. Prevalence of discordant immunologic andvirologic response in patients with AIDS under HAART in specialized care center in Brazil. Rev Inst Med Trop. 2011;53(6):301-7.

23. Kaufmann GR, Furrer $H$, Ledergerber B, Perrin L, Opravil M, Vernazza P, et al. Characteristics, determinants, and clinical relevance of CD4 T cell recovery to $<500$ cells/mm3 in HIV type 1 -infected individuals receiving potent antiretroviral therapy. Clin Infect Dis. 2005;41(1):361-72.

24. Schechter M, Tuboi SH. Discordant immunological and virological responses to antiretroviral therapy. J Antimicrob Chemother. 2006:58:506-10.

25. Teixeira Â, Valdez H, Mccune JM, Koup RA, Badley AD, Hellerstein MK, et al. Poor CD4 T cell restoration after suppression of HIV-1 replication may reflect lower thymic function. AIDS. 2001;15(14):1749-56.

26. Lubyayi L, Shkedy Z, Mwehire D, Kawuma E, Odiit M, Mukasa B, et al. Evolution of CD4 cell counts over time for HIV/AIDS patients on antiretroviral therapy (ART) in Mildmay. Biometr Biostat Int J. 2015;2(2):00025.

27. Brenchley JM, Schacker TW, Ruff LE, Price DA, Taylor JH, Beilman GJ, et al. CD4+ T Cell Depletion during all stages of HIV disease occurs predominantly in the gastrointestinal tract. J Exp Med. 2004;200(6):749-59.

28. Bastard M, Soulinphumy K, Phimmasone P, Saadani AH, Ciaffi L, Communier $\mathrm{A}$, et al. Women experience a better long-term immune recovery and a better survival on HAART in Lao People's Democratic Republic. BMC Infect Dis. 2013;13(27):9.

29. Luguterah MA. CD4+ cell counts of HIV-1 patients on antiretroviral therapy(ART) in the Builsa district hospital. Eur Sci J. 2013:9(33):299-309.

30. WHO. Guideline on when to start antiretroviral therapy and on preexposure prophylaxis for HIV; 2015.

31. Gallant JE, DeJesus E, Arribas JR, Pozniak AL, Gazzard B, Campo RE, et al. Tenofovir DF, emtricitabine, and efavirenz vs. zidovudine, lamivudine, and efavirenz for HIV. N Engl J Med. 2006:354:251-60.

32. Omeje I, Okwundu Cl. Effectiveness and safety of first-line tenofovir + emtricitabine + efavirenz for patients with HIV. Cochrane Libr. 2012;2.

\section{Submit your next manuscript to BioMed Central and we will help you at every step:}

- We accept pre-submission inquiries

- Our selector tool helps you to find the most relevant journal

- We provide round the clock customer support

- Convenient online submission

- Thorough peer review

- Inclusion in PubMed and all major indexing services

- Maximum visibility for your research

Submit your manuscript at www.biomedcentral com/submit 